\title{
Hábitos Relacionados ao Descarte Pós-Consumo de Aparelhos e Baterias de Telefones Celulares em uma Comunidade Acadêmica
}

\section{Habits Related to the Post-Consumption Discard of Mobile Phones and their Batteries within an Academic Community}

Juliana Barbosa Zuquer Giaretta

Bióloga. Especialista em Saúde Ambiental. Mestranda em Saúde Pública pela Faculdade de Saúde Pública da Universidade de São Paulo.

Endereço: Av. Dr. Arnaldo, 715, Cerqueira César, CEP 01246-904, São Paulo, SP, Brasil.

E-mail: jzuquerळusp.br

\section{Daniel Gouveia Tanigushi}

Biólogo. Doutorando em Saúde Pública pela Faculdade de Saúde Pública da Universidade de São Paulo.

Endereço: Av. Dr. Arnaldo, 715, Cerqueira César, CEP 01246-904, São Paulo, SP, Brasil.

E-mail: danieltanigushiळgmail.com.br

\section{Marcela Tashiro Sergent}

Bióloga. Realizou Iniciação Científica pelo Departamento de Saúde Ambiental da Faculdade de Saúde Pública da Universidade de São Paulo.

Endereço: Av. Dr. Arnaldo, 715, Cerqueira César, CEP 01246-904, São Paulo, SP, Brasil.

E-mail: marcela.sergentळusp.br

\section{Maria da Penha Vasconcellos}

Psicóloga Social. Doutora em Saúde Pública. Professora Associada da Faculdade de Saúde Pública. Pesquisadora do Laboratório Interdisciplinar de Estudos e Pesquisas Sociais em Saúde Pública/ LIESP/FSP-USP.

Endereço: Av. Dr. Arnaldo, 715, Cerqueira César, CEP 01246-904, São Paulo, SP, Brasil.

E-mail mpvascon®usp.br

\section{Wanda Maria Risso Günther}

Engenheira Civil e Socióloga. Doutora em Saúde Pública. Professora Associada da Faculdade de Saúde Pública da Universidade de São Paulo.

Endereço: Av. Dr. Arnaldo, 715, Cerqueira César, CEP 01246-904, São Paulo, SP, Brasil.

E-mail: wguntherळusp.br

\section{Resumo}

Cada vez mais a sociedade contemporânea incorpora em seu cotidiano equipamentos elétricos e eletrônicos, muitos deles contendo substâncias perigosas, que representam ameaças ao meio ambiente e riscos à saúde humana. Este artigo apresenta os resultados de uma pesquisa exploratória com o objetivo de relacionar comportamento de descarte pós-consumo de aparelhos e baterias de celulares, em um grupo de consumidores de telefonia móvel, que tem proximidade em seu cotidiano de trabalho e de estudo com informações sobre saúde pública e ambiental. Os resultados da pesquisa indicam que informação pode aproximar as pessoas do problema, porém não levam por si só à produção de alterações significativas sobre o que e como fazer com o descarte pós-consumo. Os participantes do estudo possibilitaram identificar, que além da informação e acesso a coletores específicos, outros aspectos e critérios pessoais ou coletivos interferem no procedimento de descarte: percepção sobre risco, valor econômico disponibilizado na compra do aparelho e vínculos afetivos, entre outros. Esses fatores podem produzir diferentes respostas dos usuários sobre como lidar com as inovações tecnológicas de uso pessoal.

Palavras-chave: Sociedade de risco; Resíduos de equipamentos elétricos e eletrônicos; Resíduos especiais; Celular; Baterias. 


\section{Abstract}

The contemporary society increasingly incorporates electric and electronic equipments (EEE) in its everyday life, many of them containing dangerous substances that represent threats to the environment and risks to human health. This article presents the results of an exploratory research with the objective of investigating the behavior of post-consumption discard of mobile phones and their batteries in a group of consumers of mobile phones who are in contact, in their work and study, with information about public and environmental health. The results of the research indicate that information can approximate the people to the problem; however, it does not lead, by itself, to the production of significant alterations on how to perform the post-consumption discard. The study's participants enabled to identify that besides information and access to specific collectors, other personal or collective aspects and criteria interfere in the discard procedure: risk perception, economic value available in the purchase of the mobile phone and affective bonds, among others. Those factors can produce different responses of users concerning how to deal with the technological innovations of personal use.

Keywords: Risk Society; Electric and Electronic Equipment Waste; Special Waste; Cell Phone; Batteries.

\section{Introdução}

As questões relacionadas à produção de resíduos na sociedade contemporânea, cada vez mais, passam a fazer parte da circulação de informações das mídias, dos desafios dos gestores públicos, das agendas de organismos internacionais e das linhas de pesquisa e estudos de comunidades acadêmicas. Se, por um lado, o tema apresenta-se como ponto de destaque no discurso e acordos políticos internacionais, por outro, pode-se observar que na esfera próxima à vida cotidiana do cidadão ainda há muito a ser construído.

Segundo Ulrich Beck (1992), o desenvolvimento técnico-científico e a maneira como esse conhecimento foi aplicado ao processo produtivo são fatores determinantes das profundas transformações impostas ao ambiente e às sociedades contemporâneas. Dialeticamente, essas transformações impulsionaram a sociedade a um patamar de conquistas e desenvolvimento técnico-econômico nunca antes experimentado, mas, ao mesmo tempo, mergulhou-a em uma atmosfera que abriga uma série de riscos de caráter socioambiental, a que o autor denominou de sociedade de risco, aquela que reparte seus males e danos. Essas mudanças, presentes e disseminadas no dia a dia da sociedade, ocorrem de forma constante, infiltrando-se de modo praticamente silencioso, imperceptível e não previsível. Rapidamente são incorporadas no cotidiano dos cidadãos e, ao mesmo tempo, provocam na sociedade, tanto no presente como no futuro, uma gama de inseguranças, angústias e incertezas.

0 processo de modernização ${ }^{1}$ e suas condicionantes, aliados a fatores como mudança de hábitos nas práticas dos cidadãos, desejos de consumo e novas condutas sociais, políticas públicas urbanas e modelos de gestão dos recursos e resíduos são aspectos a serem considerados no contexto da sociedade pós-moderna, para que venham possibilitar melhor compreensão sobre a imprevisibilidade do futuro ou, como referido por Beck (1999), sobre a necessidade de sabermos reconhecer que as sociedades produzem seus próprios riscos, que os cidadãos

1 "Refere-se aos impulsos tecnológicos de racionalização e à transformação do trabalho e da organização, mas incluiu muitas coisas mais: a mudança das características sociais e das biografias normais, dos estilos de vida e das formas de amar, das estruturas de influência e de poder, das formas políticas de opressão e de participação das concepções da realidade e das normas cognoscitivas [...]” (Beck, 1992). 
precisam minimizar seus efeitos e, ao mesmo tempo, saber conviver no seio dessa sociedade geradora de riscos.

Giddens (1998), alinhando-se às reflexões de Beck, identifica que na sociedade de risco os efeitos nefastos das atividades econômicas são considerados externalidades, não pagos pelos agentes econômicos, mas arcados por terceiros, de forma involuntária e desigual. Nesse contexto, a estratégia das empresas de externalizar os custos socioambientais, ou seja, transferi-los para a sociedade, no intuito de poupar o real causador do ônus decorrente de sua operação, embora ainda amplamente empregada, tem enfrentado resistências e encontrado cada vez menos respaldo na sociedade.

A contaminação ambiental e os agravos à saúde decorrentes da má gestão dos resíduos sólidos, inclusive aqueles do pós-consumo, têm sido computados como externalidades do sistema produtivo industrial. Resíduos do pós-consumo, entre eles os resíduos de equipamentos elétricos e eletrônicos, principalmente os que contêm substâncias perigosas, representam ameaça ao meio ambiente e risco à saúde humana, cuja gestão ambiental, no país, não se efetiva devido à ausência de uma presença mais consistente de regulação por parte do Estado.

Embora, na sociedade de risco, a expansão dos riscos não rompa em absoluto com a lógica do desenvolvimento capitalista, os efeitos secundários (sociais, econômicos e políticos) produzidos a partir dos episódios de contaminação ambiental e agravos à saúde, tornam-se importantes. Esse fato incorpora um potencial político, de organização da sociedade na defesa e na administração das situações de risco, como acidentes e catástrofes (Beck, 1992). Em decorrência desses efeitos secundários, a sociedade tem buscado, ainda que em âmbito local e de modo ainda inexpressivo, organizar estratégias de enfrentamento com base na participação social e cidadania.

No entanto, para que esse processo se efetive e produza resultados satisfatórios torna-se necessário que a reflexão crítica sobre a sociedade de risco esteja mais presente no cotidiano do cidadão, possibilitando apropriar-se de informações relevantes como forma de contribuir para uma percepção mais qualificada sobre as questões socioambientais e os riscos inerentes.
“A percepção do risco é condicionada pelas respectivas características: há riscos cuja carga simbólica, mais do que a probabilidade efetiva da sua concretização ou os seus potenciais efeitos, os torna especialmente temidos, merecerão maior atenção dos meios de comunicação social, ou ainda relevância especial para certas populações. Elencado um conjunto de riscos ambientais ou de saúde pública de caráter global" (Delicado e Gonçalves, 2007). Sendo assim, assume múltiplas formas de expressão e significados simbólicos nos diversos contextos sociais e culturais, enfatizando sua complexidade.

\section{Resíduos de Equipamentos Elétricos e Eletrônicos}

A produção de equipamentos elétricos e eletrônicos (EEE) representa um dos setores industriais que mais cresce na atualidade, impulsionada principalmente pela inovação tecnológica e padrão de consumo presentes no mundo contemporâneo. Acompanhando essa produção, há o aumento significativo da geração de resíduos de equipamentos elétricos e eletrônicos (REEE) (Schwarzer e col., 2005).

Devido à complexidade de sua composição e à presença de substâncias tóxicas, os REEE vêm ganhando importância como fonte de substâncias perigosas que podem causar danos ao ambiente e à saúde pública se descartados de maneira inadequada (Widmer e col., 2005), configurando situação de risco.

Entre os REEE mais descartados atualmente, encontram-se os aparelhos provenientes da área de tecnologia de informação, categoria em que se enquadram os aparelhos de telefonia móvel. Embora sua introdução seja recente, de 1983 para cá (Anatel, 2009), seu uso passou a fazer parte das sociedades contemporâneas como uma forma de comunicação e relacionamento, estabelecimento de vínculos, inclusão econômica e de estilo de vida, nos diversos grupos sociais, com dimensões mundiais.

Os aparelhos celulares em constante evolução nesse período também sofreram várias modificações, incorporando novas funções, passando de simples terminal de comunicação a terminal de múltiplo uso. Passaram a agregar múltiplas funções, são inclusive denominados de multifuncionais; de aparelhos para comunicação a distância, para aparelhos de múltiplos usos - GPS, internet, rádio, produção de 
imagens, reprodução de músicas, gravador, cronômetro, entre outras. Logo, as inovações tecnológicas conduziram a um acréscimo de funcionalidades e o celular passou a servir a diversos propósitos, atuando como câmera, GPS, terminal de acesso a internet, dispositivo de envio de mensagens em texto, entre outros (Nokia, 2008a), configurando-se como objeto de desejo de vários segmentos da população.

Assim, cada vez mais, parte de sua funcionalidade passa a fazer parte do modo de vida e de ser visto como objeto tecnológico de desejo de seus usuários, ou seja, indica que veio para ficar.

O uso de aparelhos móveis em diversas localidades do mundo, como uso e valor simbólico na contemporaneidade, faz parte da "incerteza científica" da sociedade de riscos em que geramos e vivemos. Conforme estudo da OMS IARS Interphone project on mobile phones and risk of brain cancer (WHO, 2009), requer atenção constante sobre seu potencial acumulativo e com possibilidade de gerar doenças com alterações na estrutura celular dos indivíduos através da radiação presente no aparelho, como no acúmulo de resíduos decorrentes da fabricação de aparelhos e baterias de descarte pós-consumo e suas substâncias perigosas para o ambiente.

No Brasil, o uso de aparelhos móveis de uso pessoal já ultrapassa os de acesso fixo e, em outubro de 2009, chegava a 166.120.788 unidades, com expressividade em todo o território nacional (Anatel, 2009).

Entretanto, o acesso aos serviços e às funcionalidades não se dá por incorporação de componentes aos aparelhos em uso, mas por sua substituição integral, resultando na substituição do aparelho atual por um mais avançado, o que resulta no descarte ou no armazenamento pós-consumo, devido à obsolescência. Esse fenômeno industrial e mercadológico, muito bem ajustado às estratégias produtivas e de marketing, denomina-se obsolescência programada, ou seja, a expectativa curta de duração de algum bem ou produto, projetado de forma que seu funcionamento ou durabilidade se efetive apenas por um período de tempo reduzido. Essa estratégia visa garantir um consumo constante, apoiando-se na insatisfação do consumidor, de forma que os bens e produtos funcionem por tempo determinado ou não atenda mais às expectativas do consumidor, tendo obrigatoriamente que ser periodicamente substituído, influindo diretamente sobre sua descartabilidade.

Além disso, o crescimento da produção desses equipamentos, acompanhado da queda de preço, desencadeou o aumento de sua taxa de descarte (Hilty, 2005). Segundo Ban (2004a), um consumidor utiliza seu aparelho celular por 18 meses em média antes de descartá-lo, mesmo que o aparelho apresente potencial de uso de 10 anos (Wright, 1999 apud Nokia, 2008a). Nos Estados Unidos, estimou-se que em 2005, 130 milhões de aparelhos celulares seriam descartados, resultando em 65 mil toneladas de resíduo (Fishbein, 2002 apud Ban, 2004b). Combinada a essa descartabilidade está a reposição dos aparelhos, que chega a representar 80\% das vendas (Antoine, 2003), que em âmbito mundial ultrapassaram 1,15 bilhões de unidades no ano de 2007 (Gartner, 2008).

Os aparelhos celulares têm estrutura e materiais de composição complexa, contendo entre 500 e 1000 componentes, grande parte composto de ampla variedade de materiais e substâncias (Nokia, 2008a). Algumas dessas substâncias são perigosas como: chumbo, retardantes de chama bromados, berílio, cromo hexavalente, arsênio, cádmio e antimônio, presentes nos aparelhos celulares (Ban, 2004a); e cádmio, níquel, cobalto e mercúrio, que podem estar presentes nas baterias (Reidler e Günther, 2003). Essas substâncias não apresentam perigo ao meio ambiente ou à saúde humana quando o aparelho está em uso, mas representam risco se liberadas ao ambiente pela disposição final em aterros, queima ou em processos de reciclagem inadequados (Nokia, 2008a). Representam ainda risco ocupacional, quando manipulados ou recuperados sem critérios técnico-sanitários, que considerem a saúde do trabalhador nas atividades inerentes.

Em um mercado de produção e circulação global, a questão dos REEE torna-se também significativa em países em desenvolvimento, devido a fatores como crescimento exponencial da telefonia móvel, elevado potencial consumidor e alta taxa de descartabilidade. Considerando-se que nesses países, na ausência de políticas públicas para o setor, a infraestrutura de coleta e encaminhamento para recuperação ou tratamento desses resíduos não acompanhou a velocidade de consumo, os resíduos 
decorrentes do descarte de aparelhos celulares vêm se tornando um problema para a saúde humana e ambiental.

A primeira resposta internacional à questão foi a Mobile Phone Partnership Initiative (MPPI), que se baseou na Convenção da Basileia, tratado internacional cujo objetivo principal foi discutir e disciplinar o transporte transfronteiriço de resíduos em âmbito mundial. Essa iniciativa envolveu fabricantes, operadoras e governos signatários da Convenção, que se comprometeram a desenvolver e implantar atividades que visavam promover os objetivos da Convenção com relação ao gerenciamento ambientalmente adequado dos aparelhos celulares em seu fim de vida (MPPI, 2003).

Com base no exposto sobre a importância desse tema para a saúde pública e ambiental, este artigo apresenta os resultados da pesquisa que teve por objetivo relacionar o grau de informação de usuários de aparelhos de celulares, partindo do pressuposto que pessoas que cotidianamente têm acesso a informações acadêmicas sobre o uso desses aparelhos tenham comportamento diferenciado em relação ao descarte de aparelhos e baterias de celulares pós-consumo.

O estudo foi realizado na Faculdade de Saúde Pública, da Universidade de São Paulo (USP), no ano de 2007. Essa unidade foi escolhida por sua singularidade, considerando que seus objetivos institucionais são de formação de pesquisadores e profissionais no campo de conhecimentos interdisciplinares, em saúde pública e ambiental.

\section{Metodologia}

Estudo exploratório com o objetivo de identificar hábitos de descarte pós-consumo de aparelhos e baterias de telefones celulares de um grupo de usuários de telefonia móvel que tem, em seu cotidiano institucional, informações sobre saúde pública e ambiental.

Considerando a natureza exploratória e as características institucionais em que ocorreu a pesquisa, estabeleceram-se alguns critérios para o levantamento das informações: convite aos participantes por meio de questionário virtual semiestruturado e identificação de retornos por segmentos - alunos, professores e funcionários. O questionário possibilitou identificar características pessoais dos participantes, hábitos relacionados ao descarte de aparelhos celulares e baterias, conhecimento e acesso a informações pertinentes, além de sugestões de locais para a coleta dos REEE, dos participantes.

O questionário foi desenvolvido em padrão HTML (Hyper Text Markup Language) para a web e ficou alojado no servidor da Faculdade de Saúde Pública. O convite para a participação da pesquisa, juntamente com o link para o acesso do questionário e uma senha individual, foi enviado aos 1606 e-mails do cadastro institucional, composto de professores, funcionários e alunos. 0 questionário ficou disponível aos participantes por 30 dias, no período entre janeiro e fevereiro de 2007 , tendo o convite para participação sido enviado duas vezes, neste período.

A opção pela utilização de um instrumento eletrônico deveu-se à diminuição do tempo para obtenção de respostas, à flexibilidade do horário de acesso ao questionário e menor ônus financeiro, quando comparado à entrevista em domicílio ou ao serviço postal (Shannon e Bradshaw, 2002).

Variáveis sociais referentes à escolaridade, idade e sexo foram coletadas e correlacionadas às respostas dadas a questões sobre o destino pós-consumo de baterias e do último aparelho celular. 0 questionário abordou aspectos relacionados ao conhecimento e às formas de divulgação das informações sobre descarte de baterias de celulares, solicitando ao entrevistado que classificasse entre Adequada, Inadequada ou Desconhecida as seguintes questões: informação sobre a legislação brasileira referente a pilhas e baterias (Brasil, 1999); divulgação das formas corretas de destino; divulgação de locais de coleta; e, por fim, informação sobre as consequências ao ambiente e à saúde humana. Além disso, foi solicitado ao entrevistado que escolhesse, entre nove opções, os meios de comunicação pelos quais gostaria de receber as informações, com relação à forma correta de destinação de baterias dos celulares. Por fim, foram solicitadas sugestões de alternativas para a realização da coleta das baterias na FSP e na USP.

As questões sobre os hábitos com relação ao destino de baterias e aparelhos celulares pós-consumo, colhidas de forma discursiva, foram catego- 
rizadas como adequadas e não adequadas para a análise final, do ponto de vista da saúde pública e ambiental.

A análise dos dados e os testes estatísticos foram realizados utilizando-se o pacote estatístico Sigmastat 2.03, com base no teste de associação de Qui-quadrado $\left(\mathrm{X}^{2}\right)$.

\section{Resultados e Discussão}

Das 1606 pessoas que receberam o convite para a participação, 223 responderam ao questionário, equivalendo à taxa aproximada de $14 \%$ de retorno. Apesar de a taxa de retorno ter sido relativamente baixa, não se pode relegar que esse sistema de inquérito eletrônico gerou mais de duas centenas de participações, obtidas em apenas um mês e com custo muito mais baixo que o que incidiria por meio de técnicas convencionais. Apesar de a participação nessa modalidade de pesquisa estar condicionada ao acesso à Internet e a um endereço de $e$-mail, esse fator não foi considerado obstáculo na pesquisa, pois a Universidade de São Paulo disponibiliza facilidades de acesso à Internet para seus professores, funcionários e alunos, assim como endereço eletrônico institucional.

O segmento que aderiu em maior número na participação da pesquisa foi o dos estudantes, que se mostrou bastante jovem e com elevado grau de escolaridade, constituído principalmente por pessoas entre 18 e 27 anos (Tabela 1), com ensino superior (Tabela 2) e do sexo feminino (79\%). Além
Tabela I - Proporção (\%) de pessoas por faixa etária (em anos), são Paulo, 2009

\section{Intervalo de Idade}

$18-27$

$28-37$

$38-47$

Mais de 48
Parcela do público

$36 \%$

$26 \%$

$23 \%$

$15 \%$
Tabela 2 - Proporção (\%) de pessoas por grau de escolaridade, São Paulo, 2009

\begin{tabular}{lc} 
Grau de Escolaridade & Parcela do público \\
Ensino médio & $6 \%$ \\
Graduação & $24 \%$ \\
Especialização & $31 \%$ \\
Mestrado & $25 \%$ \\
Doutorado & $14 \%$ \\
\hline
\end{tabular}

disso, 174 dos participantes eram alunos (78\%), 34 funcionários (15\%) e 15 professores (7\%).

Em relação aos hábitos de descarte de aparelhos celulares, dos 223 participantes da pesquisa, nove tiveram suas respostas desconsideradas por não haverem respondido corretamente ao questionário. Assim, a amostra totalizou 214 participantes e suas respostas foram categorizadas em dez grupos (Tabela 3).

Os resultados mostram que apenas $2 \%$ dos respondentes considerados não possuíam aparelho

Tabela 3 - Número e proporção (\%) das respostas referentes à destinação dada ao aparelho celular, São Paulo, 2009

\begin{tabular}{lcc} 
Destino dado pelo participante & N de respostas & \% de respostas \\
Está armazenado & 91 & 42,5 \\
Doou & 48 & 22,4 \\
Está em uso & 22 & 10,3 \\
Foi roubado & 14 & 6,6 \\
Devolveu à operadora/fabricante & 12 & 5,6 \\
Vendeu & 8 & 3,7 \\
Descartou no lixo comum & 7 & 3,4 \\
Descartou em outro local específico que não a operadora/fabricante & 5 & 2,3 \\
Não possui celular & 5 & 2,3 \\
Perdeu & 2 & 0,9 \\
\hline Total & $\mathbf{2 1 4}$ & 100 \\
\hline
\end{tabular}


celular e que $10 \%$ desses estavam com seu primeiro aparelho ainda em uso. Considerando-se apenas os que possuíram mais de um celular (187 participantes), a maior frequência de respostas foi referente ao armazenamento no domicílio (49\%), seguido pelos que doaram o aparelho para uso por outras pessoas (26\%). A devolução ao fabricante/operadora só foi relatada por $6 \%$ dos respondentes desse grupo.

Para a análise estatística, as categorias foram reagrupadas em duas: destinação adequada (devolução/local específico/doação/venda) e destinação não adequada (descarte no lixo comum/armazenamento), considerando-se apenas as categorias que caracterizaram o comportamento individual, quanto ao destino dado ao aparelho celular. Nessa análise, foram excluídas as categorias: perda, roubo, em uso e não possuir aparelho celular. As duas categorias consideradas, em associação com as variáveis sociais, foram analisadas através do teste do $\mathrm{X}^{2}$, mostrando não haver relação significativa entre a destinação (adequada e não adequada), grau de escolaridade $\left(X^{2}=5,764 ; G L=4 ; p=0,217\right)$, faixa etária $\left(X^{2}=2,66 ; G L=3 ; p=0,447\right)$ e sexo $\left(X^{2}=0,146 ; G L=\right.$ $1 ; \mathrm{p}=0,703)$.

Quanto ao hábito relacionado ao descarte das baterias de aparelhos celulares, dos 223 participantes da pesquisa, sete tiveram suas respostas desconsideradas por não responderem corretamente ao questionário. As respostas dos 216 respondentes foram distribuídas em nove categorias (Tabela 4).

Pode-se observar que $41 \%$ dos respondentes considerados nunca realizaram a troca da bateria

Tabela 4 - Número e proporção (\%) das respostas referentes à destinação dada às baterias dos aparelho celular, São Paulo, 2009

\begin{tabular}{lcc} 
Destino das baterias dos aparelhos celulares & $N^{\circ}$ de respostas & \% de respostas \\
Nunca descartou & 89 & 41,2 \\
Está armazenada & 45 & 20,8 \\
Devolveu na operadora/fabricante & 40 & 18,5 \\
Descartou em outro local especifico que não a operadora/fabricante & 20 & 9,3 \\
Descartou no lixo comum & 9 & 4,2 \\
Não possui celular & 5 & 2,3 \\
Doou & 5 & 2,3 \\
Vendeu & 2 & 0,9 \\
Foi roubada & 1 & 0,5 \\
\hline Total & $\mathbf{2 1 6}$ & 100 \\
\hline
\end{tabular}

do celular. Considerando os que tiveram que descartar a bateria (127), o destino praticado com maior frequência foi, assim como no caso dos aparelhos, o armazenamento no domicílio (35\%), seguido da devolução ao fabricante/operadora (31\%) e entrega em outros locais específicos para a coleta desses resíduos, que não aqueles mantidos pelos fabricantes ou operadoras (16\%).

Aplicando-se os mesmos procedimentos quanto ao tratamento estatístico e reagrupamento nas categorias de destinação adequada (devolução/local específico/doação/venda) e não adequada (descarte no lixo/armazenamento), os resultados mostraram não haver associação significativa entre o destino dado às baterias de celulares e grau de escolaridade $\left(\mathrm{X}^{2}=\right.$ 5,265; GL = 4; $\mathrm{p}=0,261)$, faixa etária $\left(X^{2}=2,916 ; G L=\right.$ 3; $\mathrm{p}=0,405)$ ou sexo $\left(\mathrm{X}^{2}=0,131 ; \mathrm{GL}=1 ; \mathrm{p}=0,717\right)$.

Esses resultados afastam-se daqueles encontrados por Saphores e colaboradores (2006), cujo trabalho investigou a pré-disposição dos consumidores quanto ao encaminhamento correto de seus resíduos eletroeletrônicos e concluiu que variáveis sociais como sexo e educação atuam como fatoreschave para explicar essa pré-disposição. Todavia, Diamantopoulos e colaboradores (2003), examinando a correlação entre variáveis socioeconômicas 
(sexo, estado civil, idade, número de filhos e classe social), além de outras, com o conhecimento, postura e atitudes ambientais, sugeriram que a relação entre aspectos socioeconômicos, características sociais e comportamento pró-ambiente é complexa. Apesar de encontrarem algumas relações entre variáveis sociais, incluindo idade, sexo e escolaridade, os autores enfatizaram que é difícil predizer a propensão a comportamentos pró-ambiente com base nesses critérios, pois dependendo da conjuntura essas variáveis podem ter mais ou menos influência.

Os resultados, quanto ao destino de celulares, indicaram o armazenamento como o destino mais frequente, representando $49 \%$ entre os que já trocaram de aparelho, bastante próximo ao resultado da pesquisa realizada pela Nokia (2008b) em 13 países, incluindo o Brasil, na qual $44 \%$ dos entrevistados referiram não descartar seus aparelhos mesmo desativados.

A baixa porcentagem de participantes que afirma ter devolvido à operadora/fabricante ou ter descartado seus celulares em outro local específico (Tabela 3), deve ser analisada com cuidado. Essa prática não deve ser atribuída à ausência completa de alternativas para realizá-la, pois, desde novembro de 2006, já existia iniciativa de coleta de celulares para reciclagem, realizada pela operadora de telefonia móvel Vivo (AHCIET, 2008), na época, a operadora líder de mercado com $28,85 \%$ de participação (Anatel, 2007). Mais recentemente - porém posterior ao período do inquérito - campanha semelhante foi lançada pela operadora Claro². Contudo, além de links encontrados nas homepages de ambas as operadoras, há pouca divulgação dessas campanhas, consubstanciando-se em estratégia frágil e de pouco alcance. Nesse aspecto, nota-se a necessidade de que seja intensificada a divulgação e a atuação das operadoras por meio de campanhas mais objetivas e efetivas.

Já os dois maiores fabricantes de aparelhos celulares, Nokia e Motorola (Gartner, 2008), apesar de também oferecerem programas de coleta de aparelhos em lojas, no caso da Motorola ${ }^{3}$, ou, na rede de assistência técnica, no caso da Nokia ${ }^{4}$, não disponibilizam informações de fácil acesso em suas homepages; a Samsung 5 , terceira maior companhia não traz em seu website informação a respeito.

Torna-se importante ressaltar que, apesar de existirem campanhas para incentivar a coleta seletiva, muitas vezes elas não são efetivas. Estudo realizado por Rayapura (2005), em lojas de quatro cidades participantes do programa americano de coleta e reciclagem de baterias usadas, denominado Charge Up to Recycle!, mostrou que a eficácia do programa era questionável. Fatores como desinformação dos funcionários das lojas, pouca divulgação, escassez ou pouca visibilidade dos coletores foram apontados como determinantes para sua não efetividade.

Com relação às baterias usadas, a pesquisa indicou que, entre aqueles que já efetuaram troca das baterias de seus celulares, $47 \%$ as devolveram ao fabricante/operadora ou destinaram a local de coleta específica. Somente $7 \%$ descartaram-nas em lixo comum, enquanto $35 \%$ conservaram as baterias, mesmo sem uso. É provável que essa melhora com relação ao descarte adequado de baterias, quando comparada ao descarte dos aparelhos celulares, seja atribuída à existência de outras iniciativas, desvinculadas e até mesmo anteriores àquelas relacionadas ao descarte correto de celulares; a exemplo dos programas de coletas em pontos comerciais ou da publicação da Resolução Conama 257, editada em 1999 (Brasil, 1999), cujo objetivo foi normatizar as questões referentes ao descarte de pilhas e baterias usadas, em âmbito nacional. Essas iniciativas, além de atuarem na conscientização da população, incentivaram o incremento da oferta de pontos de coleta, em adição àqueles oferecidos pelos fabricantes e operadoras. No presente caso, a categoria "local específico" contribuiu com um terço dos participantes que alegaram devolver suas baterias.

Contudo, a despeito da efetividade e da importância dos sistemas pontuais de coleta e destinação adequada, disponibilizados por instituições que não

\footnotetext{
2 Informação obtida em: <http://www.claro.com.br>. Acesso em: 10 out. 2008

3 Informação obtida em: <http://www.motorola.com/br.jsp>. Acesso em: 10 out. 2008.

4 Informação obtida em: <http://www.nokia.com.br>. Acesso em: 10 out. 2008.

5 Informação obtida em: <http://www.samsung.com.br>. Acesso em: 10 out. 2008.
} 
fabricantes e operadoras, ainda há muito por fazer. Hoje, a não existência de uma política específica que estabeleça as responsabilidades e competências e a falta de um modelo de gestão_dos REEE entravam o encaminhamento de soluções sustentáveis para a questão, tornando qualquer iniciativa apenas um paliativo, com alcance limitado e pouco eficaz.

Outro aspecto a ser considerado na inter-relação ambiente-sociedade é a complexidade existente entre o conhecimento e a prática, as relações entre o "saber/conhecer", "ter disposição para agir" e o "realmente agir". Nem sempre o nível de conhecimento ou disposição para agir estão ligados, ou se concretizam, na ação efetiva (Diamantopoulos e col., 2003).

Neste estudo, apesar de os participantes possuírem elevado grau de escolaridade (Tabela 2) e de a maioria declarar ter acesso a informações sobre as consequências ambientais e sanitárias do descarte inadequado de baterias ( $83 \%$ ), apenas uma parcela dos participantes declarou conhecer informações sobre a Resolução Conama 257/1999 (27\%), sobre a divulgação da destinação correta desses resíduos (29\%) e sobre os locais de coleta disponíveis (41\%). Ainda assim, dentre essa pequena parcela, a maioria referiu que a divulgação dessas informações é realizada de maneira inadequada $(18 \%, 21 \%$ e $38 \%$ respectivamente) (Tabela 5).

\section{Tabela 5 - Proporção de participantes (\%) segundo sua opinião sobre acesso à informação, São Paulo, 2009}

\begin{tabular}{|c|c|c|c|c|}
\hline \multirow[b]{2}{*}{$\begin{array}{l}\text { Conhecimento/Forma de } \\
\text { descarte }\end{array}$} & \multicolumn{4}{|c|}{ Informação sobre (\%) } \\
\hline & $\begin{array}{c}\text { Resolução Conama } \\
\text { n 257/99 }\end{array}$ & Destinação correta & Locais de coleta & $\begin{array}{l}\text { Consequências ao } \\
\text { ambiente e à saúde }\end{array}$ \\
\hline Desconhece & 73 & 71 & 59 & 17 \\
\hline Conhece - Inadequada & 18 & 21 & 38 & 62 \\
\hline Conhece - Adequada & 9 & 8 & 3 & 21 \\
\hline Total & 100 & 100 & 100 & 100 \\
\hline
\end{tabular}

Consultados sobre por quais meios de comunicação apreciariam obter informações sobre o descarte correto de baterias de celulares, os participantes mencionaram, para alternativas de múltipla escolha: televisão (76\%), Internet (64\%), o próprio manual do aparelho (55\%), pontos de venda (55\%), rádio (44\%), jornal (43\%), pontos de troca (40\%), revista (36\%) e outros $(8 \%)$.

Considerando as respostas com relação aos meios de comunicação a serem utilizados para maior divulgação sobre legislação e formas de descarte pós-consumo, podemos considerar que os informantes sinalizam uma baixa mobilização de operadoras e fabricantes no que tange às campanhas efetivas para esse fim.

Em relação à pergunta discursiva solicitada aos participantes sobre quais sugestões teriam quanto à forma de descarte pós-consumo, no campus da Faculdade de Saúde Pública e demais campus da Universidade de São Paulo, houve unanimidade no encaminhamento: coletores específicos para coleta seletiva, aliados à divulgação pré e pós-descarte. Foi enfatizada também a necessidade de colocação dos coletores em locais estratégicos, de fácil acesso e visualização, próximos aos coletores seletivos já instalados, na biblioteca, salas de informática, departamentos e nos corredores de circulação comum.

\section{Considerações Finais}

Os resultados indicam que a informação pode aproximar as pessoas do problema, porém, não levam por si só à produção de alterações significativas sobre como fazer o descarte pós-consumo. Os participantes do estudo possibilitaram identificar, que além da informação e da falta de coletores específicos, outros aspectos e critérios pessoais ou coletivos interferem no procedimento de descarte: percepção sobre risco, valor econômico disponibilizado na compra do aparelho e vínculos afetivos, entre outros. Esses fatores podem produzir diferentes respostas dos usuários sobre como lidar com as inovações tecnológicas de uso pessoal. 
Os gestores públicos, do setor saúde e ambiente, precisam voltar a olhar para a forma de consumo contemporâneo, que merece ser avaliada do ponto de vista da saúde das coletividades e da sustentabilidade ambiental, levando em consideração as incertezas científicas.

As indústrias de eletroeletrônicos e de marketing institucional, para venda dos produtos, devem ser responsabilizadas por não responder de forma adequada à produção e veiculação de seus bens e produtos, na perspectiva da sustentabilidade e da responsabilidade sobre tecnologias que apresentem potencial de risco à saúde pública e ambiental antes de lançarem seus bens e produtos ao consumo público. A sociedade, por sua vez, deve repensar sua conduta de consumo, considerando que não há determinismo no ato de consumir, mas que este envolve desejo, escolha, prioridades e consciência política diante das ofertas.

A tríade funcionalidade, inovação tecnológica e consumo deve sempre vir acompanhada de critérios éticos voltados ao bem comum, respeitando as heterogeneidades das condutas sociais e culturais.

\section{Referências}

\section{AHCIET - ASOCIACIÓN IBEROAMERICANA DE CENTROS DE INVESTIGACIÓN Y EMPRESAS DE TELE-COMUNICACIONES. Vivo cria programa inédito para reciclagem de celulares. [Madrid.], [20o6]. Disponível em: <http://www.ahciet.net/ actualidad/noticias/noticia.aspx?idnotic $=15981>$. Acesso em: 10 out. 2008.}

ANATEL - AGÊNCIA NACIONAL DE TELECOMUNICAÇÕES. Superada marca de 100 milhões de celulares em operação. [Brasília], [2007]. Disponível em: <http://www.anatel.gov. $\mathrm{br} /$ Portal/verificaDocumentos/documento.asp ?numeroPublicacao=139316\&assuntoPublicaca o=Marca\%2ode\%20100\%2omilhões\%2ode\%20 \%2ocelulares\%2oé\%2osuperada\%2ocom\%20 798,5\%2omil\%2onovas\%2oadesões\%2o\&camin hoRel=null\&filtro=1\&documentoPath=biblioteca/ releases/2007/release_21_02_2007.pdf.>. Acesso em: 10 out. 2008 .
ANATEL - AGÊNCIA NACIONAL DE TELECOMUNICAÇÕES. Brasil ultrapassa os 166 milhões de acessos móveis. [Brasília], [2009]. Disponível em: <http://www.anatel.gov.br/Portal/ exibirPortalInternet.do?acao=carregaNoticia\&codi go=19129. Acesso em: 21 out. 2009.

ANTOINE, P. Understanding the mobile phone market drivers. Colombes, Alcatel, 2003. Disponível em: <http://www.privateline.com/ archive/alcaatel.pdf.>. Acesso em: 10 set. 2008.

BAN - BASEL ACTION NETWORK. Mobile toxic waste: recent findings on the toxicity of end-of-life cell phones. Seattle, 2004a. Disponível em: <http:// www.ban.org/Library/mobilephonetoxicityrep. pdf.>. Acesso em: 4 out. 2008.

BAN - BASEL ACTION NETWORK. Wireless waste: basel convention's next - hazardous waste challenge. Seattle, 2004b. Disponível em: <http:// www.ban.org/Library/WirelessWaste.pdf $>$. Acesso em: 4 out. 2008.

BECK, U. Risk society: towards a new modernity. London: Sage, 1992

BECK, U. World risk society. Cambridge: Polity Press, 1999.

BRASIL. Resolução CONAMA nº 257/99, de 30 de junho de 1999. Estabelece que pilhas e baterias que contenham em suas composições chumbo, cádmio, mercúrio e seus compostos, tenham os procedimentos de reutilização, reciclagem, tratamento ou disposição final ambientalmente adequados. Diário Oficial da União, Brasília, DF, 22 jul. 1999. p. 039. Disponível em: <http://www. mma.gov.br/port/conama/>. Acesso em: 29 jul. 2008.

DELICADO, A.; GONÇALVES, M. E. Os portugueses e os novos riscos: resultados de um inquérito. Análise Social, Lisboa, v. XLII, n. 184, p. 687-718, 2007.

DIAMANTOPOULOS, A. et al. Can sociodemographics still play a role in profiling green consumers?: a review of the evidence and an empirical investigation. Journal of Business Research, Montreal, v. 56, p. 465-48o, 2003. 
GARTNER. Gartner says worldwide mobile phone sales increased 16 per cent in 2007. Egham, 2008. Disponível em: <http://www.gartner.com/it/page. jsp?id=612207>. Acesso em: 3 out. 2008.

GIDDENS, A. Risk society: the context of British politics. In: FRANKLIN, J. (Ed.). The politics of risk society. Cambridge: Polity Press, 1998. p. 23-34.

HILTY, L. M. Electronic waste - an emerging risk? Environmental Impact Assessment Review, New York, v. 25, n. 5, p. 431-435, 2005. Editorial. Disponível em: <http://www.empa.ch/plugin/ template/empa/*/51646>. Acesso em: 12 out. 2008.

MPPI - MOBILE PHONE PARTNERSHIP

INITIATIVE. Guidance document on the environmentally sound management of used and end-of-life mobile phones. Pensacola, 2003. Disponível em: < http://www.basel.int/meetings/ cop/cop8/docs/ozaze.pdf >. Acesso em: og set. 2008.

NOKIA. Integrated product policy project stage I final report: life cycle environmental issues of mobile phones. Espoo, 2008a. Disponível em: <http://ec.europa.eu/environment/ipp/mobile.htm >. Acesso em: 10 ago. 2008.

NOKIA. Global consumer survey reveals that majority of old mobile phones are lying in drawers at home and not being recycled. [Espoo], 2008b. Disponível em: <http://www.nokia.com/ A41360o1? newsid=1234291>. Acesso em: 10 out. 2008.
RAYAPURA, A. Wireless waste: the challenge of cell phone and battery recycling. New York, Inform, 2004. Disponível em: < http://www. informinc.org/reports_waste.php >. Acesso em: 11 ago. 2008.

REIDLER, N. M. V. L.; GÜNTHER, W. M. R. Impactos ambientais e sanitários causados por descarte inadequado de pilhas e baterias usadas. Revista Limpeza Pública, São Paulo, v. 6o, p. 2026, 2003 .

SAPHORES, J. M. et al. Household willingness to recycle electronic waste: an application to California. Environment and Behavior, Thoretand Oaks, v. 38, n. 2, p. 183-208, 2006.

SCHWARZER, S. et al. $\varepsilon$-waste, the hidden side of IT equipment's manufacturing and use. Geneva: UNEPE, 2005 .

SHANNON, D. N.; BRADSHAW, C. C. A Comparison of response rate, response time, and costs of mail and electronic surveys. The Journal of Experimental Education, Ann Arbor, v. 7o, n. 2, p. 179-192, 2002.

WHO - WORLD HEALTH ORGANIZATION. WHO handbook on establishing a dialogue on risks from electromagnetic fields. Geneva, 2002. Disponível em: <http://www.who.int/peh-emf/publications/ en/>. Acesso em: 21 out. 2009.

WIDMER, R. et al. Global perspectives on e-waste. Environmental Impact Assessment Review, New York, v. 25, n. 5, p. 436-458, 2005. 